\title{
ASSOCIATION OF PENTRAXIN-3, GALECTIN-3 AND MATRIX METALLOPROTEINASE-9/TIMP-1 WITH CARDIOVASCULAR RISK IN RENAL DISEASE PATIENTS
}

\author{
Milica Miljković1, Aleksandra Stefanović ${ }^{1}$, Nataša Bogavac-Stanojević ${ }^{1}$, Sanja Simić-Ogrizović2 \\ Jerka Dumić ${ }^{3}$, Darko Černe ${ }^{4}$, Zorana Jelić-Ivanović ${ }^{1}$ and Jelena Kotur-Stevuljević ${ }^{1}$ \\ ${ }^{1}$ Department of Medical Biochemistry, Faculty of Pharmacy, University of Belgrade, Belgrade, Serbia; \\ ${ }^{2}$ Department of Nephrology, Clinical Center of Serbia, Belgrade, Serbia; ${ }^{3}$ Department of Medical Biochemistry, \\ Faculty of Pharmacy and Biochemistry, University of Zagreb, Zagreb, Croatia; \\ ${ }^{4}$ Department of Clinical Biochemistry, Faculty of Pharmacy, University of Ljubljana, Ljubljana, Slovenia
}

\begin{abstract}
SUMMARY - Inflammation, apoptosis and extracellular remodeling play significant roles in cardiovascular disease (CVD) underlying the major causes of mortality in renal patients. In 19 pre-dialysis patients, 21 dialysis patients and 20 control subjects, the concentrations of pentraxin-3, galectin-3, MMP-9 and TIMP-1 were determined by ELISA. CVD risk was calculated according to the Framingham risk score algorithm. Pentraxin-3 was increased in renal patients compared to healthy controls $(\mathrm{p}<0.001)$. In contrast, galectin-3 was reduced in hemodialysis patients compared to pre-dialysis patients and controls $(\mathrm{p}<0.001)$. In addition, MMP-9 and TIMP-1 were elevated in renal patients compared to controls $(\mathrm{p}<0.01$ and $\mathrm{p}<0.001$, respectively). Logistic regression analyses disclosed associations of galectin-3, MMP-9, pentraxin-3 and glomerular filtration with calculated CVD risk score. Combined testing of pentraxin-3, galectin-3, MMP-9 and glomerular filtration rate can discriminate renal patients with high and low risk of a coronary event.
\end{abstract}

Key words: Kidney diseases; Pentraxin-3; Galectin-3; Matrix-metalloproteinase-9; Tissue inhibitor of matrix metalloproteinase-1; Risk factors; Risk assessment; Cardiovascular diseases

\section{Introduction}

Chronic kidney disease (CKD) represents a significant health problem worldwide. The increasing prevalence of hypertension and diabetes as the main factors will further enhance the number of patients developing end-stage renal disease $(\mathrm{ESRD})^{1}$.

Cardiovascular disease (CVD), chronic low-grade inflammation and protein-energy wasting are present in a large proportion of patients with advanced $\mathrm{CKD}^{2}$,

Correspondence to: Milica Miljković, $M D, M S$, Department of Medical Biochemistry, Faculty of Pharmacy, Vojvode Stepe 450, P. Box 146, 11000 Belgrade, Serbia

E-mail: milicammiljkovic@gmail.com

Received September 5, 2016, accepted May 29, 2017 and each of these factors independently predicts their outcome $e^{2,3}$.

Pentraxin-3, an acute-phase protein, plays an important role in the regulation of inflammatory reactions, clearance of apoptotic cells and resistance to pathogens ${ }^{2}$. Tong et al..$^{2}$ showed that pentraxin-3 has a predictive value for mortality in CKD.

Progressive renal disease is a consequence of disequilibrium between the increased synthesis of extracellular matrix components and their decreased degradation, which occurs as a result of imbalanced matrix metalloproteinase (MMP) activities and their tissue inhibitors (TIMP), leading to nephron $\operatorname{loss}^{4}$. Increased inflammation and oxidative stress enhance MMP expression and activity, thus increasing the prevalence of 
numerous diseases including atherosclerosis, nephritis and fibrosis ${ }^{5}$. MMP-9 is a zinc-dependent enzyme involved in tissue remodeling which includes degradation of extracellular matrix components, as well as the processing of non-matrix substrates ${ }^{4}$. In contrast, TIMP-1 is a specific endogenous inhibitor that binds MMP-9 and suppresses its activity 5 .

Galectin-3, a molecule with diverse biological activities, might play a role within the complex maze of connections that link inflammation, extracellular matrix remodeling and apoptosis. The former is a multifunctional lectin with a broad range of actions including anti-adhesion, binding advanced glycation endproducts (AGE), regulation of gene expression and controlling cell proliferation and death ${ }^{6}$. However, more recent evidence suggests that galectin-3 is an anti-apoptotic and anti-fibrotic agent, thus functioning to prevent further CKD development ${ }^{7}$. Due to its diversity of actions, the role of galectin-3 in progressive renal disease remains controversial.

From 1948, the Framingham study strived to identify common factors contributing to CVD over a long period of time. Hypertension, smoking, hyperlipidemia and age were found to be independent risk factors for CVD. The study employed the Framingham risk score (FRS) algorithm in order to predict an acute coronary event within the next 10 years ${ }^{8}$.

Our present study aimed to assess circulating pentraxin-3, galectin-3, MMP-9 and TIMP-1 concentrations in different stages of CKD, in both dialysis and non-dialysis patients, as well as in a control group. We also assessed association between plasma concentrations of pentraxin-3, galectin-3, MMP-9, TIMP-1 and estimated glomerular filtration rate (eGFR) with the FRS. Using pentraxin-3, galectin-3 and MMP-9/ TIMP-1 as markers which are in various ways involved in the pathology of renal disease and eGFR as a common indicator of kidney function, we tried to find out whether there is difference in the FRS between different stages of kidney failure.

\section{Material and Methods}

\section{Subjects}

This study included 40 renal disease patients from the Department of Nephrology, Clinical Centre of Serbia, Belgrade. Nineteen of them were pre-dialysis patients with CKD stage 2-4, not requiring hemodialysis (10 men and 9 women, mean age $53.5 \pm 18.54$ years), while the remaining 21 patients (15 men and 6 women, mean age $53.8 \pm 14.41$ years) were ESRD patients receiving dialysis [average duration 52.3 (26.8102.4) months]. The original kidney diseases in CKD and ESRD patients were: chronic glomerulonephritis $(n=6)$, nephroangiosclerosis $(n=3)$, diabetic nephropathy $(n=9)$, polycystic kidney disease $(n=3)$, other $(n=14)$ and unknown diagnosis $(\mathrm{n}=5)$. ESRD patients on thrice-weekly maintenance hemodialysis treatment (each time 4-5 hours) received a bicarbonate-based solution using polyamide and polysulfone low-flux or high-flux membranes. CKD patients with some form of glomerulonephritis as the main disease received corticosteroids or other immunosuppressive therapy according to general protocols. The control group consisted of 20 healthy subjects free of inflammation, neurological dysfunction, history of $\mathrm{CVD}$, renal, gastrointestinal, pulmonary, hepatic and oncologic disease not taking any prescribed medication.

The study was planned according to the ethical guidelines detailed in the Declaration of Helsinki. The Ethics Committee of the Clinical Center of Serbia and the Ethics Committee of the Faculty of Pharmacy, University of Belgrade evaluated and approved the study protocol. Informed consent was voluntarily obtained from all study participants.

\section{Sample collection}

Blood samples were collected after a 12-h fasting period. Serum was separated by centrifugation at $1500 \mathrm{xg}$ for $10 \mathrm{~min}$, aliquoted and stored at $-80{ }^{\circ} \mathrm{C}$ for up to one month until analysis. Blood was collected from patients immediately prior to dialysis.

\section{Biochemical analyses}

Total cholesterol and triglycerides were measured by standard automated enzymatic methods (Biosystems S.A., Barcelona, Spain) using ILab 300+ (Instrumentation Laboratory, Milan, Italy). Plasma HDL-C was determined using a direct assay (Biosystems S.A., Barcelona, Spain), whereas LDL-C cholesterol concentration was calculated using the Friedewald formula. Serum urea, creatinine, uric acid, total proteins and glucose were measured by routine laboratory methods (Bio Systems S.A., Barcelona, Spain) with an 
ILab $300^{+}$analyzer. The eGFR was calculated using the Modification of Diet in Renal Disease equation $(\mathrm{MDRD})^{9}$.

\section{ELISA}

Serum concentrations of pentraxin-3, galectin-3, MMP-9 and TIMP-1 were determined by ELISA (R\&D systems, Minneapolis, USA).

\section{Framingham risk score calculation}

The risk of CVD was calculated according to the FRS algorithm. Calculation of FRS was based on age, gender, smoking, blood pressure, total and HDL cholesterol as coronary risk factors. According to this score, all study participants were divided into three categories indicating low (<10\%), medium (10\%-20\%) and high (>20\%) risk of an acute coronary event within the next 10 years ${ }^{8}$.

\section{Statistical analyses}

Data are shown as mean \pm standard deviation (SD) for normally distributed variables, or as geometric mean with $95 \%$ confidence interval $(95 \% \mathrm{CI})$ or as median and interquartile range for parameters not normally distributed. Differences among continuous variables were assessed using ANOVA or Kruskal-Wallis test, where appropriate. Analyses of categorical variables used the $\chi^{2}$-test for contingency tables. A value of $\mathrm{p}<0.05$ was considered statistically significant. In renal patients, the possible independent association between CVD risk and concentrations of galectin-3, pentraxin-3, MMP-9, TIMP-1 and eGFR was tested by binary logistic regression. The low-risk category was used as the reference group and was coded 0 , while the high-risk group was coded 1 . Three models were tested, as follows: Model 1 - pentraxin-3, galectin-3, MMP-9; Model 2 - pentraxin-3, galectin-3, glomerular filtration; and Model 3 - pentraxin-3, galectin-3, MMP-9, glomerular filtration. We constructed receiver operating characteristic (ROC) curves with the predictive probabilities from different logistic regression models and performed pair-wise comparisons using the areas under the ROC curve (AUCs). According to the Hosmer and Lemeshow ${ }^{10}$ rules for the logistic models, the discriminative abilities of the models were classified per their AUC values as poor: $(0.5 \leq \mathrm{AUC}<0.7)$, acceptable $(0.7 \leq \mathrm{AUC}<0.8)$, excellent $(0.8 \leq \mathrm{AUC}<0.9)$ or outstanding $(\mathrm{AUC} \geq 0.9)^{10}$
For all analyses, the SPSS software $\left(\mathrm{IBM}^{\oplus} \mathrm{SPSS}^{\oplus}\right.$ version 22.0) was used.

\section{Results}

Table 1 contains data on the subjects involved in this study and the results of biochemical analyses within the study groups (CKD-pre-dialysis patients, ESRD-dialysis patients and healthy controls). Decreased HDL-C $(\mathrm{p}<0.01)$ was evident in renal patients in comparison with healthy subjects. HDL-C was also significantly lower in patients on dialysis $(\mathrm{p}<0.01)$. As expected, dialysis patients showed increased creatinine compared to pre-dialysis patients and controls. Serum concentrations of urea, creatinine and uric acid were significantly higher in dialysis patients compared with pre-dialysis patients and controls. Differences in serum concentrations of total and LDL-C, triglycerides and fasting glucose between the groups were not statistically significant $(p>0.05)$. As expected, after taking into account all the results and analyzing the FRS algorithm, we found that renal disease patients had an increased risk of CVD development as compared to the control group, but there was no difference between the subgroups of renal patients.

Differences between pre-dialysis patients, dialysis patients and controls in the concentrations of pentraxin-3, galectin-3, MMP-9 and TIMP-1 are shown in Table 2. Pentraxin-3 was significantly increased in both groups of renal patients compared to controls $(p<0.001)$. In contrast, galectin-3 was reduced in dialysis patients compared to the pre-dialysis and control groups $(p<0.001)$. In addition, MMP-9 and TIMP-1 were elevated in renal patients compared to controls $(\mathrm{p}<0.01$ and $\mathrm{p}<0.001$, respectively).

In the present study, we investigated different models in order to discriminate renal patients with high and low risk of CVD according to FRS values. To accomplish this, we constructed ROC curves with predictive probabilities and calculated AUCs (Table 3). Only combinations between parameters with significant AUC values are reported. According to the Hosmer and Lemeshow rule, the AUC (0.732) for Model 2, which included pentraxin-3, galectin-3, MMP-9 and glomerular filtration, was acceptable. However, a pair-wise comparison of ROC curves showed that this improvement was not statistically significant $(\mathrm{p}=0.453)$. 
Table 1. Demographic characteristics and standard biochemical parameters in pre-dialysis, dialysis patients and control group

\begin{tabular}{|l|l|l|l|l|}
\hline Variable & Control group & Pre-dialysis patients & Hemodialysis patients & $\mathrm{p}$ value \\
\hline Age $(\mathrm{yrs})$ & $46.7 \pm 10.01$ & $53.5 \pm 18.54$ & $52.6 \pm 13.74$ & 0.282 \\
Gender, male/female & $12 / 8$ & $10 / 9$ & $15 / 6$ & 0.466 \\
FRS, $\%$ & $3.4(2.0-5.7)$ & $21.2(15.7-28.8)$ & $20.1(15.7-25.9)$ & $<0.001^{\mathrm{b}, \mathrm{c}}$ \\
eGFR, $\mathrm{mL} / \mathrm{min} / 1,73 \mathrm{~m}^{2}$ & $90 \pm 10.1$ & $17.4 \pm 11.08$ & $6.2 \pm 2.33$ & $<0.001^{\mathrm{a}, \mathrm{b}, \mathrm{c}}$ \\
Glucose, $\mathrm{mmol} / \mathrm{L}$ & $5.1(4.820-5.46)$ & $5.4(4.80-7.32)$ & $5.3(4.72-6.15)$ & 0.189 \\
Total cholesterol, mmo//L & $4.9 \pm 0.99$ & $5.2 \pm 1.34$ & $4.5 \pm 1.42$ & 0.198 \\
HDL-C, mmol/L & $1.6(1.43-1.90)$ & $0.9(0.92-1.07)$ & $0.8(0.66-0.93)$ & $<0.01^{\mathrm{a}, \mathrm{b}, \mathrm{c}}$ \\
LDL-C, $\mathrm{mmol} / \mathrm{L}$ & $2.9(2.53-3.03)$ & $3.1(2.56-3.78)$ & $2.6(2.14-3.13)$ & 0.314 \\
Triglycerides, $\mathrm{mmol} / \mathrm{L}$ & $1.1(0.88-1.38)$ & $1.5(1.21-1.97)$ & $1.6(1.22-2.09)$ & 0.097 \\
Uric acid, $\mu \mathrm{mol} / \mathrm{L}$ & $345 \pm 85.4$ & $546 \pm 125.8$ & $422 \pm 103.1$ & $<0.01^{\mathrm{a}, \mathrm{b}}$ \\
Creatinine, $\mu \mathrm{mol} / \mathrm{L}$ & $84.1(78.8-89.8)$ & $363(281.7-467.7)$ & $824(699.9-972.3)$ & $<0.01^{\mathrm{a}, \mathrm{b}, \mathrm{c}}$ \\
Urea, $\mathrm{mmo} / \mathrm{L}$ & $5.6(5.04-6.96)$ & $21.7(18.92-24.55)$ & $22.5(19.11-24.30)$ & $<0.01^{\mathrm{b}, \mathrm{c}}$ \\
\hline
\end{tabular}

Data are expressed as mean \pm standard deviation; creatinine, triglycerides, HDL-C and LDL-C are presented as geometric mean and 95\% confidence interval (95\% CI) derived from log-normal values; urea and glucose are shown as median and interquartile range; continuous variables were compared using ANOVA or Kruskal-Wallis test; Tukey's post hoc test was used for subgroup differences; categorical variables (gender) were compared using the $\chi^{2}$-test; FRS $=$ Framingham risk score; LDL-C $=$ low density cholesterol; HDL-C $=$ high density

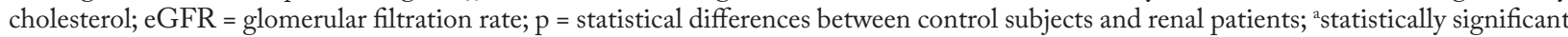
differences between pre-dialysis and dialysis patients; ${ }^{\mathrm{b}}$ statistically significant differences between pre-dialysis patients and control group; ${ }^{c}$ statistically significant differences between dialysis patients and control group

Table 2. Concentrations of pentraxin-3, galectin-3, matrix metalloproteinase-9 (MMP-9) and tissue inbibitor of matrix metalloproteinase-1 (TIMP-1)

\begin{tabular}{|l|l|l|l|l|}
\hline Variable & Control group & Pre-dialysis patients & Hemodialysis patients & $\mathrm{p}$ value \\
\hline Pentraxin-3 $(\mathrm{ng} / \mathrm{mL})$ & $0.39(0.218-0.727)$ & $1.31(0.880-1.961)$ & $1.77(1.144-2.745)$ & $<0.001^{\mathrm{b}, \mathrm{c}}$ \\
Galectin-3 $(\mathrm{ng} / \mathrm{mL})$ & $2.4(2.058-3.986)$ & $2.24(1.674-2.894)$ & $0.82(0.512-1.602)$ & $<0.001^{\mathrm{a}, \mathrm{c}}$ \\
MMP-9 $(\mathrm{ng} / \mathrm{mL})$ & $141(94-211)$ & $376(275-515)$ & $304(236-392)$ & $<0.01^{\mathrm{c}}$ \\
TIMP-1 $(\mathrm{ng} / \mathrm{mL})$ & $138(115-166)$ & $515(398-665)$ & $484(416-563)$ & $<0.001^{\mathrm{b}, \mathrm{c}}$ \\
\hline
\end{tabular}

Concentrations of pentraxin-3, MMP-9 and TIMP-1 are presented as geometric mean and 95\% confidence interval derived from lognormal values; galectin-3 concentration is median and interquartile range; continuous variables were compared using ANOVA or KruskalWallis test; categorical variables (gender) were compared using the $\chi^{2}$ test; $\mathrm{p}=$ statistical differences between control subjects and renal patients; ${ }^{a}$ statistically significant differences between pre-dialysis and dialysis patients; ${ }^{\mathrm{b}}$ statistically significant differences between pre-dialysis patients and control group; 'statistically significant differences between dialysis patients and control group

Table 3. Results of ROC curve analysis for discriminating subjects with high cardiovascular disease (CVD) risk from subjects with low CVD risk

\begin{tabular}{|l|l|l|l|l|}
\hline & AUC & $\begin{array}{l}\text { Confidence } \\
\text { interval }\end{array}$ & $\begin{array}{l}\text { Standard } \\
\text { error }\end{array}$ & $\mathrm{p}^{\mathrm{a}}$ \\
\hline Model 1 & $0.700^{\mathrm{b}}$ & $0.505-0.855$ & 0.102 & \\
Model 2 & $0.732^{\mathrm{b}}$ & $0.536-0.878$ & 0.094 & \\
Model 3 & $0.716^{\mathrm{b}}$ & $0.519-0.867$ & 0.096 & 0.453 \\
\hline
\end{tabular}

Model 1 = pentraxin-3, galectin-3 and MMP-9; Model 2 = pentraxin-3, galectin-3 and glomerular filtration; Model 3 = pentraxin-3, galectin-3, MMP-9 and glomerular filtration; ${ }^{a} \mathrm{p}$ values for testing differences in AUCs between Model 1, Model 2 and Model

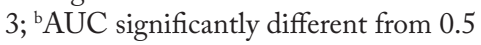

\section{Discussion}

Inflammation in CKD is one of the most important factors involved in initiating and progression of atherosclerosis, which is the main cause of morbidity and mortality in these patients. Increased inflammation in renal pathology may be explained by the presence of other illnesses, elevated oxidative stress, bioincompatible dialyzers, urinary tract infections, and increased production/decreased clearance of inflammatory cytokines ${ }^{11}$.

Pentraxin-3 (PTX3), an acute phase protein, is produced by a variety of tissues and cells, as well as in 


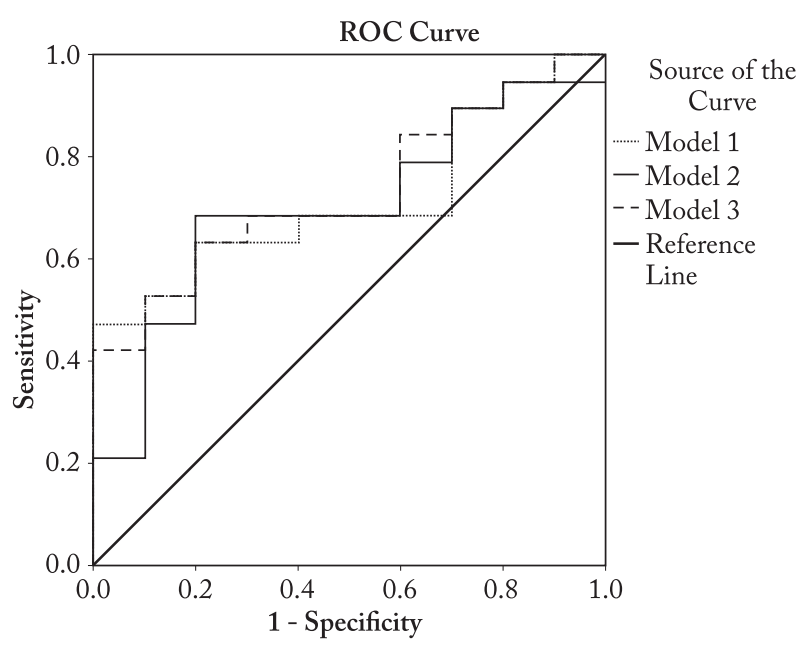

Fig. 1. Comparison of ROC curves:

Model 1 - pentraxin-3, galectin-3 and MMP-9;

Model 2 -pentraxin-3, galectin-3 and glomerular

filtration; and Model 3 - pentraxin-3, galectin-3,

MMP-9 and glomerular filtration.

the human renal cortex, medulla, glomeruli, and in the mesangial cells after stimulation with interleukin-1 (IL-1) and tumor necrosis factor- $\alpha(\mathrm{TNF}-\alpha)^{12}$. In our study, we showed that both patient groups had higher PTX3 than controls, with the highest concentration tending to be in dialysis patients (Table 2). Increased PTX3 levels could be explained as a consequence of impaired kidney function and its enhanced synthesis and release in peripheral tissues ${ }^{13}$. Given that multiple studies have reported a negative correlation between PTX3 concentration and glomerular filtration in $\mathrm{CKD}^{2,14}$, increased PTX3 could also be explained by its decreased clearance. PTX3 is a prototype of long pentraxins; a large molecule with molecular weight of $40.6 \mathrm{kD}$ characterized by a pentameric structure, which can result in increased retention during uremia ${ }^{15}$. A recent finding also suggests that PTX3 can induce morphological changes in mesangial cells, causing contraction and consequential reduction in the glomerular filtration area ${ }^{16}$. Furthermore, considering that these patients are permanently in a low-grade inflammatory state, PTX3 could be involved in the innate immune response against pathogens, regulation of inflammatory reactions, as well as in the removal of apoptotic cells ${ }^{11}$. In addition, our present study found markedly higher PTX3 concentration in patients undergoing dialysis (Table 2). A pathological uremic milieu can cause enhanced release of IL-1 $\beta$ and TNF- $\alpha$ which induce production of PTX3 leading to continuous systemic low-grade inflammation ${ }^{17}$. In agreement with our findings is a study by Rusnati et al., which suggested that PTX3 expression was probably related to the processes of matrix deposition, angiogenesis and tissue repair ${ }^{18}$.

Mounting evidence indicates that besides dyslipidemia, inflammation and oxidative stress, extensive vascular remodeling contributes to the initiation and/or progression of $\mathrm{CKD}^{19}$. Matrix metalloproteinases and their TIMPs play an important role in maintaining the equilibrium between the formation and degradation of extracellular matrix (ECM) proteins ${ }^{4}$. Considering that the main effect of MMPs is degradation, it is well documented that in the early stages of kidney disease MMPs contribute to the breakdown of collagen type $\mathrm{IV}$, the primary component of the ECM in glomerular basal membranes and mesangial matrix ${ }^{20}$. Our results indicated that pre-dialysis and dialysis patients had elevated concentrations of MMP-9 and TIMP-1 in comparison with controls (Table 2), probably indicating that increased production of MMP-9 would result in excessive degradation of the $\mathrm{ECM}^{21}$. In contrast, incorrect timing for MMP inhibition during disease has been described with increased TIMP inhibition and subsequent decreased MMP activity, resulting in deposition of ECM in CKD and renal fibrosis ${ }^{22,23}$. Increased levels of TIMP-1 were present in the patients suggesting that prolonged increased inhibition of MMP-9 could have been a factor for the development of fibrosis at a later period ${ }^{23}$. Previous findings suggested that oxidative stress and inflammation could be additional factors that induce MMP-9 expression and synthesis ${ }^{18,24}$. As MMP-9 is released by neutrophils, monocytes and macrophages during the course of an inflammatory response, increased inflammation found in these patients could be a possible reason for elevated levels of MMP-9 and consequently TIMP-1 in dialysis and non-dialysis groups compared with controls. Further evidence also indicates that this imbalance between MMP-9 activity and appropriate TIMP-1 inhibition is associated with atherosclerotic development in CKD, as well as with disease progression ${ }^{22}$.

Galectin-3 is a multifunctional $\beta$-galactosidebinding lectin responsible for many physiological and pathophysiological processes in the human body. It is involved in organogenesis, in the production of proinflammatory cytokines, the induction of oxidative stress, 
in alternative macrophage activation and in apoptosis ${ }^{6}$. However, recent evidence suggests protective effects of galectin-3. It enhances matrix remodeling, protection from fibrosis, and it is a receptor for $\mathrm{AGE}^{25}$. AGEs are glycated proteins or lipids present in many different cell types and implicated in both micro- and macrovascular complications of diabetes, which are the main causes of $\mathrm{CKD}^{26}$. Galectin-3 has been recently identified as an AGE receptor with high affinity for binding, internalization and degradation of $\mathrm{AGE}^{25}$. In contrast to Receptor for Advanced Glycation End products (RAGE) receptors, which promote tissue damage through the induction of oxidative stress, galectin-3 removes AGE and prevents renal injury ${ }^{27}$. In the present study, we showed that dialysis patients had decreased galectin-3 compared to pre-dialysis patients and controls, implicating reduced AGE removal from tissue and circulation. In addition, it has been demonstrated that AGEs promote ECM deposition via regulation of various cytokines ${ }^{26}$. We assume that decreased galectin-3 results in elevated AGE levels and enhanced uptake by RAGE receptors, subsequently followed by increased oxidative stress and ECM deposition.

As mentioned above, ECM remodeling is a critical process in renal pathology. Besides MMP and TIMP equilibrium, which is important for balancing synthesis, deposition and degradation, it has been suggested that galectin-3 may represent a second major pathway impacting on ECM remodeling ${ }^{1}$. Cuttle et al. demonstrated that tissue architecture of the interstitial matrix in galectin-3-deficient mice was more disorganized compared to wild type mice ${ }^{28}$. This finding implies that the anti-fibrotic effects of galectin- 3 might be a consequence of enhanced ECM turnover. Our data demonstrate decreased galectin-3 in dialysis patients compared to pre-dialysis patients and controls, presumably indicating poor regulation of ECM organization in dialysis patients. In an animal fibrosis model, the severity was significantly increased in galectin-3-deficient mice compared to wild type counterparts after unilateral ureteral obstruction ${ }^{29}$. This indicates the potential protective role of galectin-3 in attenuation of fibrosis severity during advanced stages of chronic kidney injury. Intracellular galectin-3 is a well-known anti-apoptotic factor, primarily localized in the cytoplasm where it inhibits activation of caspases, in a similar way as Bcl-2. It has also been shown that galec- tin-3 enhances recovery of tubular cells through limitation of apoptosis and promotion of cell proliferation during chronic kidney injury. Taking into consideration all these facts, decreased galectin-3 concentration in dialysis patients might indicate increased apoptotic processes, which lead to more profound chronic renal failure ${ }^{29}$.

The analysis of ROC curves and AUCs revealed the combination of galectin-3, pentraxin-3, MMP-9 with glomerular filtration rate to be the best discriminator between patients with low and high risk of CVD development. As expected, FRS confirmed previous findings that renal patients had an increased risk of a coronary event compared with healthy subjects. We also found that in addition to glomerular filtration, galectin-3, pentraxin-3 and MMP-9 could be potent predictors of high CVD risk in renal patients. Considering these findings, we assume that differentiation of renal patients with low and high CVD risk could be the potential clinical significance of this research. The relatively small number of renal patients in our study may represent a limitation. Further studies with larger sample sizes are needed to re-evaluate our current observations.

\section{Conclusion}

Our results provide a robust link between inflammation, ECM organization and apoptosis, which forms the basis for future in-depth studies. Long-term low-grade inflammation represented with increased pentraxin-3 can induce an imbalance between MMP9 and TIMP-1 leading to fibrosis in end-stage renal patients. This misbalance can be potentiated by decreased galectin- 3 in dialysis patients. Our results also confirmed the diverse roles of galectin-3, which besides its proinflammatory role also protects renal tubules from chronic injury by limiting apoptosis and fibrosis. All the above-mentioned interactions contribute to the increased risk of CVD, which is the leading mortality cause in renal disease patients.

\section{Acknowledgment}

This work was supported by a grant from the Ministry of Education, Science and Technological Development, Republic of Serbia (Project number: 175035). 


\section{References}

1. Couser WG, Remuzzi G, Mendis S, et al. The contribution of chronic kidney disease to the global burden of major noncommunicable diseases. Kidney Int. 2011;80(12):1258-70. doi: 10.1038/ki.2011.368

2. Tong M, Carrero JJ, Qureshi AR, et al. Plasma pentraxin 3 in patients with chronic kidney disease: associations with renal function, protein-energy wasting, cardiovascular disease, and mortality. Clin J Am Soc Nephrol. 2007;2(5):889-97. doi: 10.2215/CJN.00870207

3. Stenvinkel P. Inflammation in end-stage renal disease: the hidden enemy. Nephrology (Carlton). 2006;11(1):36-41. doi: 10.1111/j.1440-1797.2006.00541.x

4. Marson BP, Figueiredo CP,Tanus-Santos JE. Imbalanced matrix metalloproteinases in cardiovascular complications of endstage kidney disease: a potential pharmacological target. Basic Clin Pharmacol Toxicol. 2012;110(5):409-15. doi: 10.1111/j.1742-7843.2012.00863.x

5. Dimas G, Iliadis F, Grekas D. Matrix metalloproteinases, atherosclerosis, proteinuria and kidney disease: linkage-based approaches. Hippokratia. 2013;17(4):292-7.

6. Dumic J, Dabelic S, Flögel M. Galectin-3: an open-ended story. Biochim Biophys Acta. 2006;1760(4):616-35.

7. Li LC, Li J, Gao J. Functions of galectin-3 and its role in fibrotic diseases. J Pharmacol Exp Ther. 2014;351(2):336- 43. doi: 10.1124/jpet.114.218370.

8. Wilson P, D'Agostino R, Levy D, et al. Prediction of coronary heart disease using risk factor categories. Circulation. 1998; 97 (18):1837-47. doi:org/10.1161/01.CIR.97.18.1837

9. Levey AS, Bosch J, Lewis JB, et al. A more accurate method to estimate glomerular filtration rate from serum creatinine: a new prediction equation. Modification of Diet in Renal Disease Study Group. Ann Intern Med. 1999;16(6):461-70. doi: 10.7326/0003-4819-130-6-199903160-00002

10. Hosmer DW, Lemeshow S. Assessing the fit of the model. Applied logistic regression. John Wiley and Sons: New York, 2000; p. 160-4. doi: 10.1002/0471722146.ch5

11. Kaysen GA, Kumar V. Inflammation in ESRD: causes and potential consequences. J Ren Nutr. 2003;13(2):158-60. doi: http://dx.doi.org/10.1053/jren.2003.50021

12. Nauta AJ, Haij S, Bottazzi B, et al. Human renal epithelial cells produce the long pentraxin PTX3. Kidney Int. 2005;67(2): 543-53. doi: 10.1111/j.1523-1755.2005.67111.x

13. Lech M, Rommele C, Anders HJ. Pentraxins in nephrology: C-reactive protein, serum amyloid $\mathrm{P}$ and pentraxin-3. Nephrol Dial Transplant. 2012;28 (4):803-11. doi: https://doi.org/10.1093/ndt/gfs448

14. Boehme M, Kaehne F, Kuehne A, et al. Pentraxin 3 is elevated in haemodialysis patients and is associated with cardiovascular disease. Nephrol Dial Transplant. 2007;22(8):2224-9. doi: $10.1093 / \mathrm{ndt} / \mathrm{gfl} 747$

15. Speeckaert MM, Speeckaert R, Carrero JJ, et al. Biology of human pentraxin 3 (PTX3) in acute and chronic kidney disease. J Clin Immunol. 2013;33(5):881-90. doi: $10.1007 /$ s10875-013-9879-0
16. Deban L, Jaillon S, Garlanda C, et al. Pentraxins in innate immunity: lessons from PTX3. Cell Tissue Res. 2011;343(1): 237-49. doi: 10.1007/s00441-010-1018-0.

17. Yilmaz MI, Sonmez A, Ortiz A, et al. Soluble TWEAK and PTX3 in nondialysis CKD patients: impact on endothelial dysfunction and cardiovascular outcomes. Clin J Am Soc Nephrol. 2011;6(4):785-92. doi: 10.2215/CJN.09231010.

18. Rusnati M, Camozzi M, Moroni E, et al. Selective recognition of fibroblast growth factor- 2 by the long pentraxin PTX3 inhibits angiogenesis. Blood. 2004;104(1):92-9.

doi:10.1182/blood-2003-10-3433

19. Drueke TB, Massy ZA. Atherosclerosis in CKD: differences from the general population. Nat Rev Nephrol. 2010;6(12): 723-35. doi: 10.1038/nrneph.2010.143.

20. Pawlak K, Pawlak D, Mysliwiec M. Circulating b-chemokines and matrix metalloproteinase-9/tissue inhibitor of metalloproteinase-1 system in hemodialyzed patients - role of oxidative stress. Cytokine. 2005;31(1):18-24. doi: 10.1016/j.cyto.2004.12.020

21. Rysz J, Banach M, Stolarek RA, et al. Serum metalloproteinases MMP-2, MMP-9 and metalloproteinase tissue inhibitors TIMP-1 and TIMP-2 in patients on hemodialysis. Int Urol Nephrol. 2011;43(2):491-8. doi: 10.1007/s11255-009-9683-1

22. Ronco P, Chatziantoniou C. Matrix metalloproteinases and matrix receptors in progression and reversal of kidney disease: therapeutic perspectives. Kidney Int. 2008;74:873-8. doi: 10.1038/ki.2008.349

23. Zhao H, Dong Y, Tian X, et al. Matrix metalloproteinases contribute to kidney fibrosis in chronic kidney diseases. World J Nephrol. 2013;2(3):84-9. doi: 10.5527/wjn.v2.i3.84

24. Bahrehmand F, Vaisi-Raygani A, Kiani A, et al. Matrix metalloproteinase 9 polymorphisms and systemic lupus erythematosus: correlation with systemic inflammatory markers and oxidative stress. Lupus. 2015;24(6):597-605. doi: $10.1177 / 0961203314559085$.

25. Zhu W, Sano H, Nagai R, et al. The role of galectin-3 in endocytosis of advanced glycation end products and modified low density lipoproteins. Biochem Biophys Res Commun. 2001; 280(4):1183-8. doi: 10.1006/bbrc.2001.4256

26. Schleicher E, Friess U. Oxidative stress, AGE, and atherosclerosis. Kidney Int Suppl. 2007;106:S17-26. doi: 10.1038/sj.ki.5002382

27. Pricci F, Leto G, Amadio L. Role of galectin-3 as a receptor for advanced glycosylation end products. Kidney Int. 2000;58: S31-S39. doi: 10.1046/j.1523-1755.2000.07706.x

28. Cuttle L, Nataatmadja M, Fraser JF, et al. Collagen in the scarless fetal skin wound: detection with picrosirius polarization. Wound Repair Regen. 2005;13(2):198-204. doi: 10.1111/j.1067-1927.2005.130211.x

29. Okamura D, Pasichnyk K, Lopez-Guisa JM, et al. Galectin-3 preserves renal tubules and modulates extracellular matrix remodeling in progressive fibrosis. Am J Physiol Renal Physiol. 2011;300(1):245-53. doi: 10.1152/ajprenal.00326.2010. 


\title{
Sažetak \\ UDRUŽENOST PENTRAKSINA-3, GALEKTINA-3 I MMP-9/TIMP-1 S KARDIOVASKULARNIM RIZIKOM U BOLESNIKA S BUBREŽNOM BOLEŠĆU
}

\author{
M. Miljković, A. Stefanovic, N. Bogavac-Stanojević, S. Simić-Ogrizović, J. Dumić, D. Černe, \\ Z. Jelić-Ivanović i J. Kotur-Stevuljević
}

Upala, apoptoza i remodeliranje ekstracelularnog matriksa igraju značajnu ulogu u razvoju kardiovaskularnih bolesti (KVB) koje su glavni uzrok smrtnosti kod bubrežnih bolesnika. Kod 19 prijedijaliznih i 21 dijaliznog bolesnika, kao i kod 20 zdravih kontrolnih osoba koncentracije pentraksina-3, galektina-3, MMP-9 i TIMP-1 određene su pomoću tehnike ELISA. Rizik od KVB izračunat je prema Framinghamskom algoritamu. Pentraksin-3 je bio povećan kod bubrežnih bolesnika u usporedbi sa zdravim kontrolama $(\mathrm{p}<0,001)$. Nasuprot tome, galektin-3 je bio smanjen kod bolesnika na hemodijalizi u odnosu na predijalizne bolesnike i kontrole $(\mathrm{p}<0,001)$. Uz to, vrijednosti MMP-9 i TIMP-1 su bile povišene kod bubrežnih bolesnika u usporedbi s kontrolama $(\mathrm{p}<0,01 \mathrm{i} \mathrm{p}<0,001)$. Logističke regresijske analize pokazale su povezanost udruženih galektina-3, MMP-9, pentraksina-3 i glomerularne filtracije s izračunatim rezultatom rizika od KVB. Kombinirana ispitivanja pentraksina-3, galektina-3, MMP-9 i glomerularne filtracije mogla bi razlikovati bubrežne bolesnike s visokim i niskim rizikom od koronarnog događaja.

Ključne riječi: Bubrežne bolesti; Pentraksin 3; Galektin 3; Matriksna metaloproteinaza 9; Tkivni inhibitor matriksne metaloproteinaze 1; Rizični čimbenici; Rizik, procjena; Kardiovaskularne bolesti 